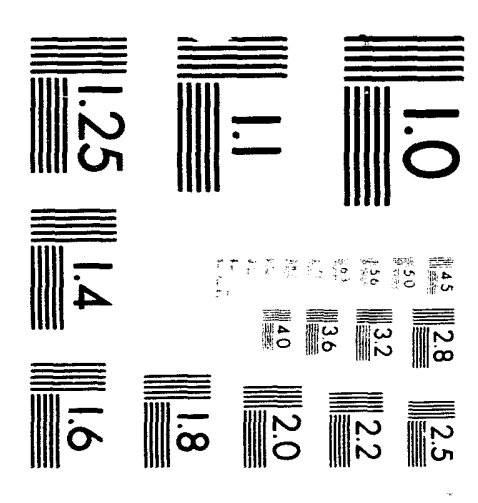



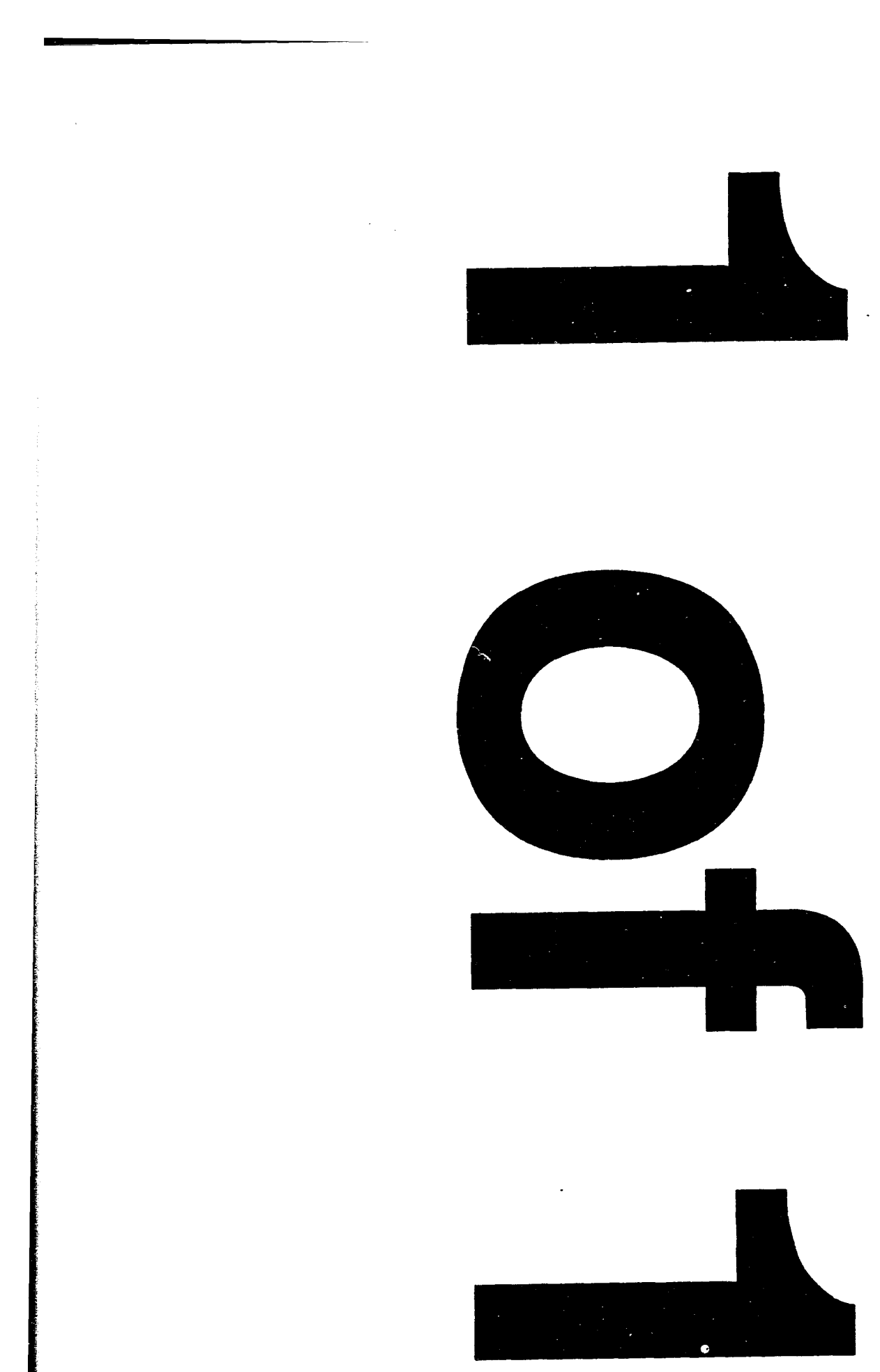
TITLE: Microwave Assisted Chemical Vapor Infiltration

AUTHOR(S): David J. Devlin

Submitted to: DOE, Advanced Industrial Concepts Materials Program

\section{DISCLAIMER}

This report was prepared as an account of work sponsored by an agency of the United States Government. Neither the United States Government nor any agency thereof, nor any of their employees, makes any warranty, express or implied, or assumes any legal liability or responsibility for the accuracy, completeness, or usefulness of any information, apparatus, product, or process disclosed, or represents that its use would not infringe privately owned rights. Reference herein to any specific commercial product, process, or service by trade name, trademark, manufacturer, or otherwise does not necessarily constitute or imply its endorsement, recommendation, or favoring by the United States Government or any agency thereof. The views and opinions of authors expressed herein do not necessarily state or reflect those of the United States Government or any agency thereof. 


\title{
MICROWAVE ASSISTED CHEMICAL VAPOR INFILTRATION
}

\author{
D.J. Devlin \\ Materials Science and Technology Division \\ Los Alamos National Laboratory \\ Los Alamos, NM 87545
}

\section{INTRODUCTION}

The purpose of this program is to develop a new process for the fabrication of ceramic matrix composites by chemical vapor infiltration. CMC's have been identified as candidate materials for applications ranging from hot gas filtration to automotive engine components capable of higher operating temperatures, reduced wear, and improved energy efficiency. These material have seen little commercial application largely due to the expense associated with processing. The need for lower cost processing is apparent. The present commercial process developed by SEP and licensed to DuPont employs an isothermal diffusion limited infiltration. Processing times are on the order of weeks to months with interruptions for regrinding and opening of closed pores. Batch processing with large furnaces intended for economy of scale are employed. However, costs are still prohibitively high for most application. Significantly reduced processing times have been demonstrated using forced CVI methods developed at ORNL. However this approach is not suitable to large scale batch processing and is limited to simple shapes. The microwave assisted CVI approach intends to incorporate the advantages of forced CVI (thermal gradient processing) with its reduced processing times, while maintaining the possibility of large scale reactors without limitations on part geometry.

The approach centers on the use of microwave heating of ceramic materials with several distinct advantages resulting. The prime advantage lies in the ability of microwave heating to produce inverted thermal gradients. This may be accomplished by direct volumetric heating of the preform with gradients established by convective and radiative losses near the surface. Alternatively the unique ability of microwaves to selectively heat one phase or component may be exploited. For example seeding of a preform with an appropriate material to generate a hot region where preferential deposition can occur is possible.

\section{TECHNICAL PROGRESS}

\section{Summary}

This period has been devoted in part to the exploration of material systems suitable for MACVI processing. A number of potential processing schemes are possible 
using combinations of absorbing and transparent material as composite components. This includes the use of an absorbing preform (nicalon fiber) combined with a transparent matrix (silicon nitride). Composites $5 \mathrm{~cm}$ in diameter by $1 \mathrm{~cm}$. thick have been fabricated to densities of $65 \%$ theoretical. Processing times for these materials are under 20 hours. Higher densities will require additional microwave power now possible with the new reactor. The most effective MACVI scheme will involve the use of a transparent fiber with an absorbing matrix. The hot spot will be initiated by appropriate treatment of the central region of the preform To this end alumna fibers with pretreatments to control thermal gradients has been explored. Nextel 610 fibers have been effectively pretreated carbon coating resulting in preferential heating in the interior of the preform. Possible matrix materials include siliconized silicon carbide, doped silicon carbide, alumna and zirconia. A patent for MACVI has been issued 10/19/93.

\section{Milestone}

Fabrication of dense ceramic matrix composite by microwave CVI with mechanical properties testing. End 9/93.

A new reactor has been designed, constructed and installed. The system is expected to eliminate the previous years difficulties due to limitations in power. Experiments to deposit $\mathrm{Si}_{3} \mathrm{~N}_{4}$ in Nicalon ${ }^{\mathrm{TM}}(\mathrm{SiC})$ cloth substrates were conducted in water cooled bell jar inserted into a modified Microwave Materials Technologies model 10-1300 multimode microwave furnace. This 1300 watt furnace, which operates at 2.45 $\mathrm{GHz}$, was modified so that additional convective (air) cooling could be supplied within the cavity. The samples were mounted on a $5 \mathrm{~cm}$ diameter quartz tube centered over the thermocouple and exhaust orifices. The quartz tube was fixed to the base plate with silicon cement. The reactant gas inlet line was attached to a hole drilled through the base plate at a position where gases entered the bell jar on the exterior of the quartz tube supporting the sample. This allows reactant gases to pass through the sample as they are exhausted to vacuum.

The chemicals used for deposition of $\mathrm{Si}_{3} \mathrm{~N}_{4}$ were silane and ammonia, reacting in excess hydrogen according to: $3 \mathrm{SiH}_{4}+4 \mathrm{NH}_{3}=\mathrm{Si}_{3} \mathrm{~N}_{4}+12 \mathrm{H}_{2}$. Flow rates were 50 sccm silane, $500 \mathrm{sccm}$ ammonia, and $2000 \mathrm{sccm}$ hydrcgen. System pressure was 300 Torr. Power levels typically were in the range of 800-900 watts with an internal substrate temperature of approximately $950^{\circ} \mathrm{C}$. Substrates were 10 stacked circular $(5 \mathrm{~cm}$ diameter) Nicalon ${ }^{\mathrm{TM}}$ cloth layers. Figure 1 shows a cloth stack before and after the infiltration run. 


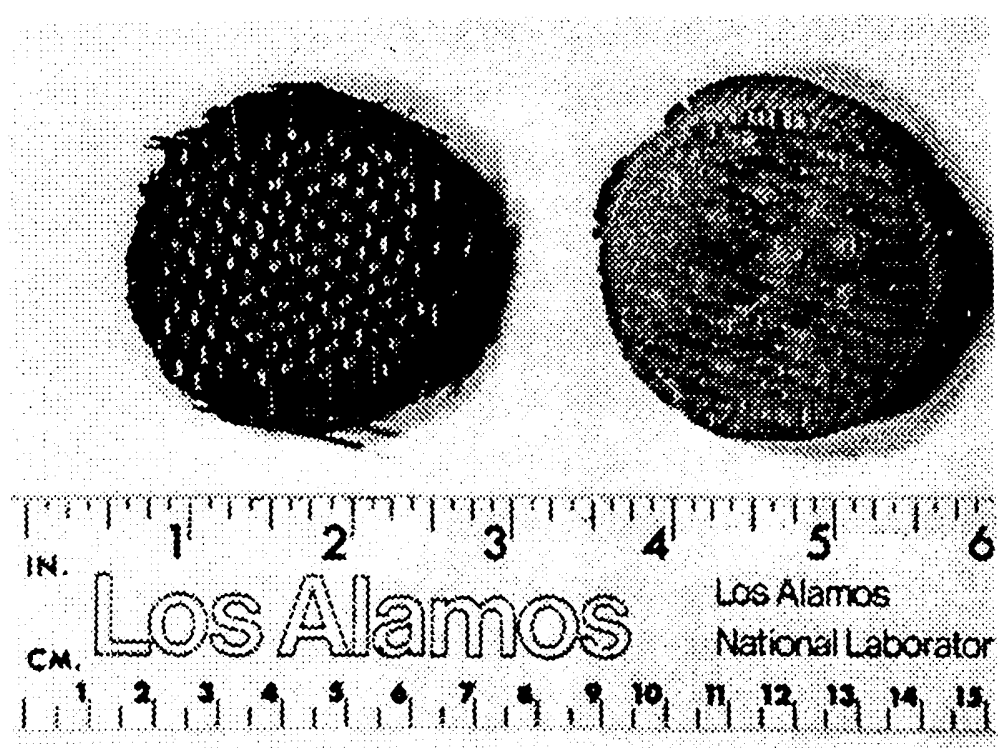

Eigure 1. Cloth before and after infiltration.

For the densified cloth shown in figure 1 , the initial weight was $6.46 \mathrm{gm}$ while the final weight following $29.5 \mathrm{hrs}$ of infiltration was $26.78 \mathrm{gm}$. Figure 2 shows a cross-section of

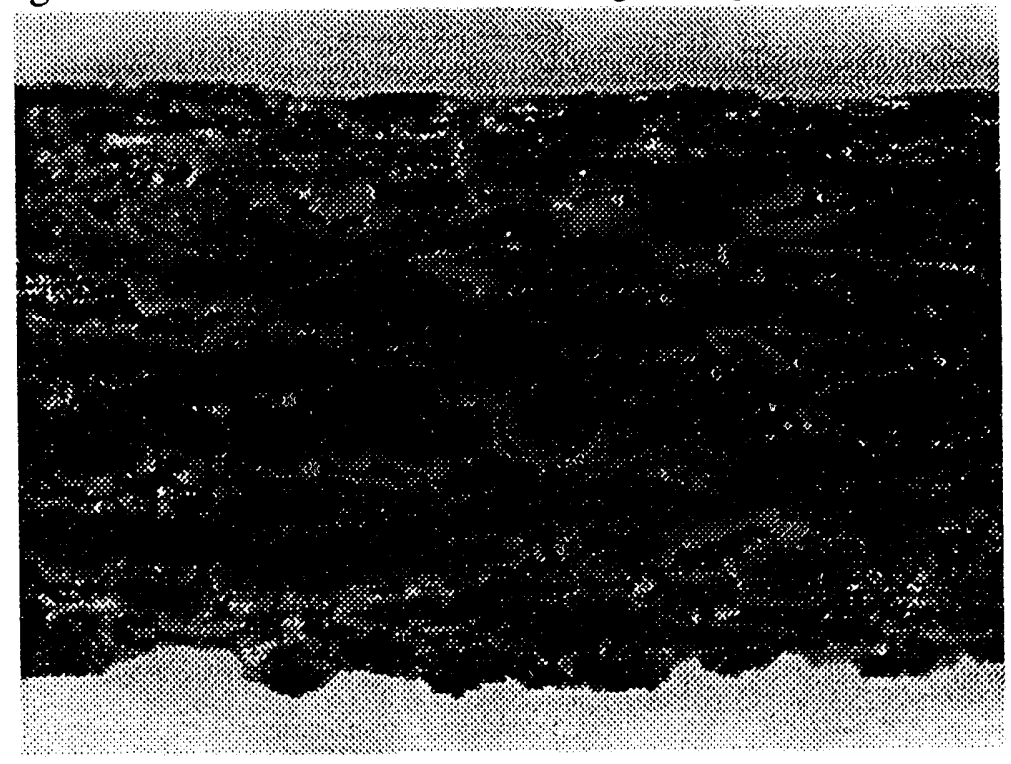

Eigure 2. Cross-section of $\mathrm{Si}_{3} \mathrm{~N}_{4}$ infiltrated cloth.

the $\mathrm{Si}_{3} \mathrm{~N}_{4}$ infiltrated cloth stack, which had a height of approximately $1 \mathrm{~cm}$.

These experiments highlight two process development issues requiring additional attention. The first is associated with non-uniform $\mathrm{Si}_{3} \mathrm{~N}_{4}$ deposition occurring within the cloths. The infiltrated stacks had regions of high porosity. The darker areas seen in the infiltraied stack shown in Figure 1 are indications of this. Since the CVI was done under forced flow conditions with relatively high flow rates, this effect was thought to be the result of cooling of certain cloth regions by the (cool) flowing gases. Additional 
experiments are needed to optimize the flow rate, inlet gas temperature, and microwave power input level in order to avoid this cooling phenomenon. The second issue is related to initial porosity and packing density of the cloth layers. The stacks used in these experiments were loosely held in a microwave transparent ceramic receptacle. The initial porosity was high, on the order of $89 \%$. While a significant amount of $\mathrm{Si}_{3} \mathrm{~N}_{4}$ was deposited, the final porosity of the disc was still on the order of $60 \%$. Although this density is far too low for most applications, it must be noted that if the initial porosity were in the range more commonly used for CVI (i.e. $\sim 40-45 \%$ ), final densities in the range of $80-85 \%$ would have been attained with the amount of $\mathrm{Si}_{3} \mathrm{~N}_{4}$ deposited during the run. Densities in this range are competitive with existing conventional CVI processes for infiltrating disc shaped cloth lay-ups and are high enough for many applications. Furthermore, the required weight gains can apparently be obtained in approximately 30 hrs of CVI time, using microwave assisted CVI. Again, these times are competitive with existing forced flow technologies. Methods to hold the cloth layers in a compressed state are under investigation. While compressing the preform may be required in infiltrating cloth lay-ups, the ultimate use of 3-dimensional woven structures should remove the need for preform compression. Mechanical testing of these materials was not undertaken due to the relatively low density.

A new six kilowatt microwave CVI reactor has been designed in conjunction with Cober electronics. The system constructed by Cober has been shipped and installed at LANL. the complete reactor is shown in figure \#. The essential features of the system are listed below:

Cylindrical Cavity/Vacuum Can (approximately 18" diameter, 33" length).

-- stainless steel construction, mode stirrer and vacuum seals rated for corrosive gas duty

-- interior Teflon coated (including mode stirrer)

-- removable interior base tray (stainless steel)

-- external water cooled jacket , $6 \mathrm{~kW}$ duty

-- viewports: 2 -four inch diameter viewports on cavity side (one/side)

-- fittings: $\quad 2-\mathrm{KF} 50$ ports on top of cavity

8 -KF 25 ports on bottom ( 2 of the 8 possibly KF 50 )

- Microwave Generator

$2-\mathrm{KF} 25$ ports on load cell compartment (for purge gases)

-- 6 kilowatts, $2.45 \mathrm{GHz}$, with low ripple filter

-- forward and reflected power meters

-- closed loop feedback controller, configured for both thermocouple and fiber optic inputs

- In-situ Balance Assembly

-- monitor sample weight in-situ ( $1 \mathrm{~kg}$ capability with $0.1 \mathrm{~g}$ readability)

- Data Acquisition System

-- interfaces for Macintosh computer (computer supplied by LANL) 
-- record/display temperature, forward \& reflected power, weight change, pressure.

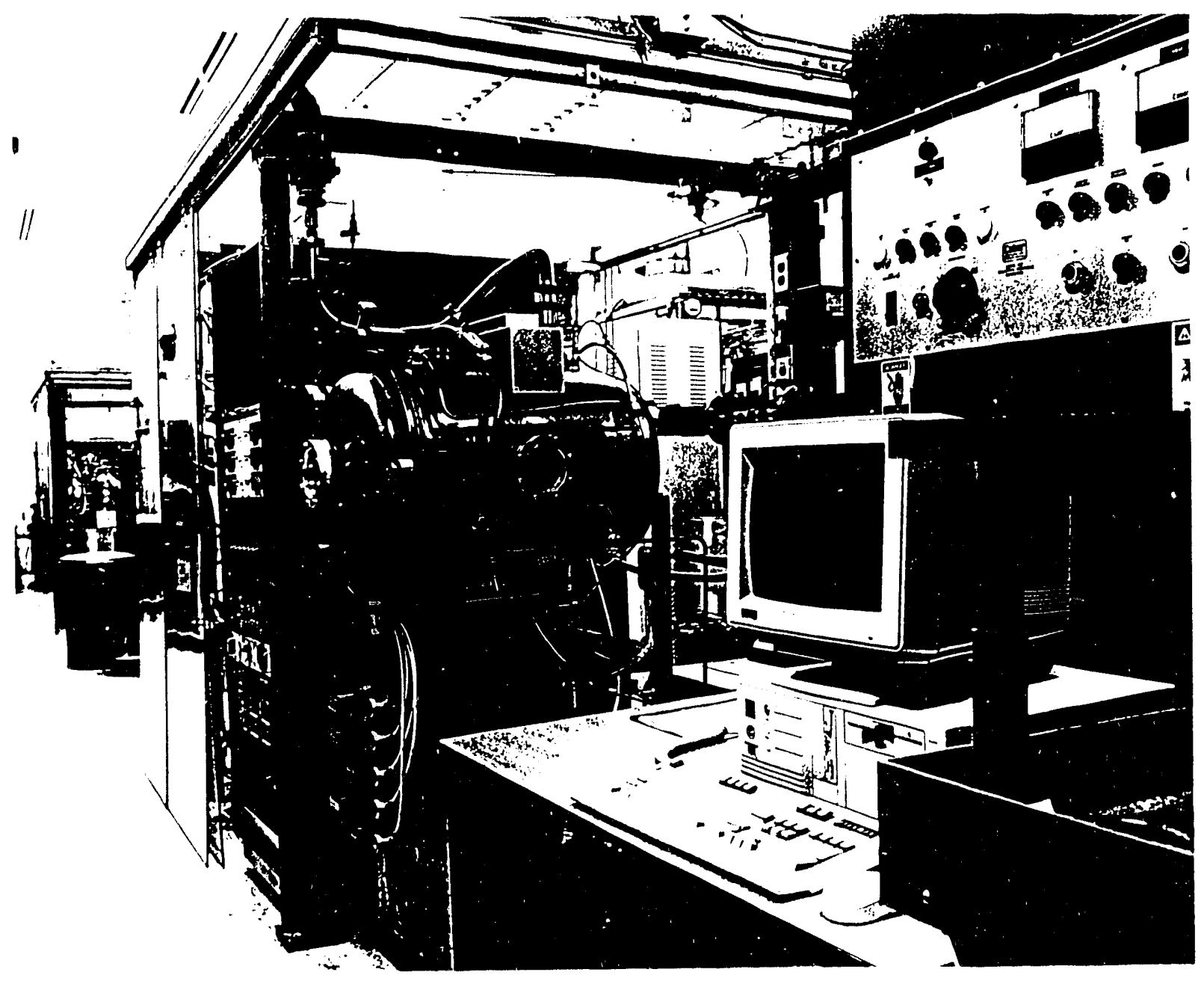

Six kilowatt microwave CVI reactor.

An Accufiber eight channel, fiber optic, high temperature measurement and control system has been purchased. This system will be used for monitoring temperature gradients within the preform and potentially incorporated within the process control system of the new reactor. Investigations using Nextel 610 high purity fibers have been undertaken. Recent results from the AIC program "Microwave Processing of Ceramic oxide Filaments", have demonstrated microwave heating of alumna fibers by applying a carbon coating. Using this approach woven cloths nextel have been treated in the center regions of a lay up resulting in preferential heating in the interior of the preform. This approach does not rely on convective or radiative losses to produce a thermal gradient. The use of an absorbing matrix material will be required for this process and is under investigation. 


\section{PRESENTATIONS:}

D. J. Devlin and R.P. Currier, "Ceramic Matrix Composites by Microwave Assisted CVI"(Invited Paper) Microwaves: Theory and Applications in Materials Processing II Symposium, 95th American Ceramic Society Annual Meeting, Cincinnati, Ohio 1993.

D.J.Devlin, R.P.Currier, R.S. Barbero, B.F. Espinoza, "Chemical Vapor Infiltration with Microwave Heating" 17th Annual Conference and Exposition on Composites and Advanced Ceramics, Cocoa Beach, Fl. January 1993.

D.J. Devlin, "Microwave Assisted Chemical Vapor Infiltration" presented at the Materials Research Society December 1991 Meeting, Symposium R, Boston, Ma.

D.J Devlin, R.P.Currier, R.S. Barbero, B.F Espinoza, "'Microwave Assisted Chemical Vapor Infiltration", Advanced Industrial Concepts Annual Review Meeting, Oak Ridge Tennessee, June 7-9, 1993.

\section{PUBLICATIONS:}

D.J. Devlin, R.P. Currier, R.S. Barbero, B.F. Espinoza, and N. Elliot, "Microwave Assisted Chemical Vapor Infiltration", Mat. Res. Soc. Symp. Proc. 250: 245 (1992).

D.J.Devlin, R.P.Currier, R.S. Barbero, B.F. Espinoza, "Chemical Vapor Infiltration with Microwave Heating" , Ceramic Engineering \& Science Proceedings, Vol 14, No. 9-10 p 761-67, 1993.

D. J. Devlin and R.P. Currier, "Ceramic Matrix Composites by Microwave Assisted CVI"(Invited Paper) Microwaves: Theory and Applications in Materials Processing II, to be published in Ceramic Transactions

\section{HONORS AND AWARDS}

None

\section{PATENTS/DISCLOSURES}

U.S. Patent No. 5254374 "Chemical Vapor Infiltration using Microwave Energy", Issued 10/19/93.

\section{LICENSES}

None 
INDUSTRIAL INPUT AND TECHNOLOGY TRANSFER

NONE

COST SHARING

NONE

\section{HIGHLIGHTS}

Silicon carbide reinforced composites have been fabricated using existing MMT microwave reactor. A new 6 kilowatt microwave reactor has been designed, constructed, and installed. A patent for MACVI has been issued. 
PROJECT SUMMARY

\title{
ADVANCED INDUSTRIAL CONCEPTS MATERIALS (AICM) PROGRAM
}

\author{
PROJECT TITLE: MICROWAVE ASSISTED CHEMICAL VAPOR INFILTRATION
}

PHASE: FY93

COMPLETION DATE: FY95

\author{
PERFORMING ORGANIZATION: Los Alamos National Laboratory \\ PRINCIPAL INVESTIGATORS David J. Devlin, (505) 667-9914 \\ Materials Science and Technology Division \\ MailStop E-549, Los Alamos, NM 87545
}

PHASE OBJECTIVE: Fabricate dense ceramic matrix composites using inverted thermal gradients produced by microwave heating. Design construct and install a new reactor capable of achieve the desired goal of high density ceramic composites with reduced processing time. Explore key processing issues, including absorption of microwave energy in matrix and reinforcement materials of practical interest.

ULTIMATE OBJECTIVES: A more energy efficient and economically competitive process for producing reinforced ceramic matrix composites. A process capable of uniform density composites without shape limitations. Demonstrate the benefits microwave heating brings to ceramic composite processing using chemical vapor infiltration techniques.

TECHNICAL APPROACH: Exploit microwave induced inverted thermal gradients to promote inside-out densification of composites by chemical vapor infiltration. Use multimode microwave cavities as infiltration reactors. Establish inverted thermal gradients in substrates using microwave driven volumetric heating together with heat losses at surfaces through radiation and convection. establish inverted gradients using selective microwave heating by seeding preforms or coating specific regions of the preform with an absorbing material. Use vapor infiltration to introduce gases which react in the hot region to densify the composite. Explore various processing strategies, such as diffusion limited, forced and pulsed reactant flows. Examine the effects of various microwave heating schedules and power level modulation schemes. Explore alternative process chemistries. Use basic results in process optimization and projections on commercial viability and scale-up

PROGRESS: Silicon carbide reinforced silicon nitride composites were fabricated using microwave heating and inverted thermal gradients. While high densities were not achieved the results do suggest significantly reduced processing times are possible. Methods for selectively heaing interior regions of fiber preforms by coating with a microwave absorbing material have been developed. A large six kilowatt microwave reactor capable of producing high density material has been designed, constructed and installed at LANL.

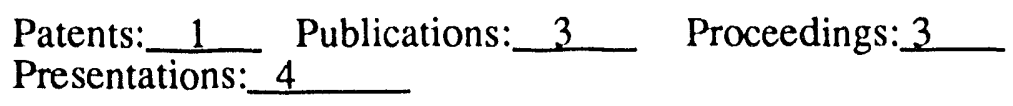

ACCOMPLISHMENTS: Proof-of-concept phase is complete. Have shown microwave heating can be combined with vapor infiltration to densify composites. Silicon carbide reinforced silicon nitride composites have been fabricated. New and more promising 
approaches to the development and control of inverted thermal gradients for MACVI have been developed. A more robust and powerful reactor has been installed.

\author{
Licenses: \\ 0 \\ Follow-on Products: \\ Industry Workshops: \\ Technology Transfer: Pursuing the possibility of industrial collaborations with a \\ number of interested companies.
}

\title{
PROJECT TITLE: MICROWAVE ASSISTED CHEMICAL VAPOR INFILTRATION
}

CRITICAL ISSUES: With the new reactor in place and sufficient power the critical issue the silicon nitride composite will be increasing the initial preform density. Present cloth layups are at most 20 volume percent fiber. A higher initial density will allow a further reduction in processing time while achieving higher final densities. This may be accomplished with a microwave transparent fixture for use during the early stages of infiltration. Once the cloths are effectively stuck together the fixture can be removed. Control of the thermal gradients can be difficult due problems associated with thermal run away and the reliance of convective and radiative loss at the surface. An alternative scheme is to use a transparent preform (alumna fiber), treated in the conter of the preformwith an absorbing coating. Heating will occur initially in the treated area, not relying on losses at the surface resulting in a tightly controlled hot spot. Infiltration with a microwave absorbing matrix will than lead to rapid inside-out densification. A fiber and treatment scheme has been successfully developed. A critical issue will be the development and control of a suitable matrix chemistry.

FUTURE PLANS: Further optimize the silicon carbide reinforced silicon nitride using the new reactor. The objective is to achieve sufficient density to warrant mechanical testing of the composite. Develop a processing scheme for treated alumna fiber $\mathrm{s}$ with an absorbing matrix.

POTENTIAL PAYOFF: A successful microwave assisted infiltration process has the potential to eliminate many limitations encountered with conventional approaches to composite fabrication by chemical vapor infiltration. First, constraints on substrate geometry could be removed. Second, more spatially uniform, high density composites should be attainable. Third, relatively short processing times should be possible when pulsed reactant flows are employed. Fourth, machining operations to reopen closed pores should not be necessary since densification would occur from the inside-out. Finally, use of a cold wall reactor will minimize unwanted reaction on the walls and fixtures thereby saving on reactant costs and minimizing waste production. 


\section{MICROWAVE ASSISTED CHEMICAL VAPOR INFILTRATION}

\section{Problem:}

Currently continuously reinforced ceramic matrix composites are fabricated by an isothermal chemical vapor infiltration approach typified by the SEP process. The fabrication of silicon carbide composites by this method requires weeks to months of processing time. Materials can cost up to $\$ 5000 / \mathrm{b}$, prohibitively expensive for most intended applications. The need for lower cost processing is apparent.

\section{Results:}

The use of microwave heating of ceramic fiber preforms is being explored as a means of developing an improved rapid process for the fabrication of composites by chemical vapor infiltration. The volumetric and preferential heating of certain materials by microwaves provides a means of establishing inverted thermal gradients in a preform. The result is the ability to rapidly infiltrate the preform developing the matrix from the inside-out. Using this technique silicon carbide reinforced silicon nitride composites have been fabricated. Furthermore, the feasibility of pretreating regions of a preform, resulting in preferential heating has been demonstrated. A patent for the method has been issued.

\section{Significance-for energy conservation:}

The development of cost a effective process for the fabrication of ceramic matrix composites will enable the introduction of these materials into areas of technology directly related to energy conservation. These include heat engine and automotive applications were increased efficiency is the objective. In addition the method its self will conserve energy by drastically reducing processing times. 

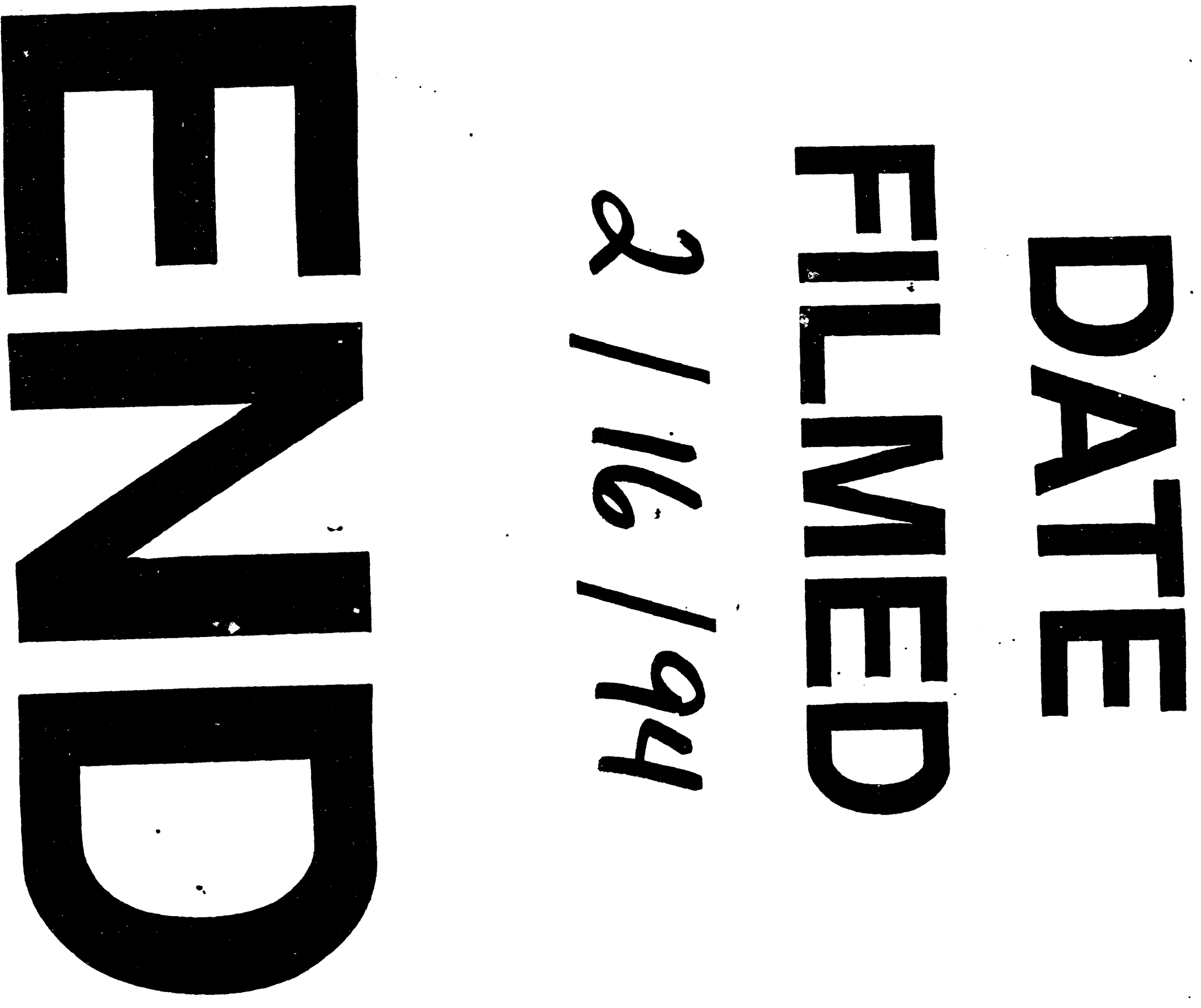
